\title{
The IMAGEN Story: A Framework for Restoring Indigenous Girl Societies
}

\author{
Kelly Hallman \\ Population Council \\ Lisa Polen \\ Population Council \\ Katey Peck \\ Population Council
}

Follow this and additional works at: https://knowledgecommons.popcouncil.org/departments_sbsr-pgy

Part of the Family, Life Course, and Society Commons, Gender and Sexuality Commons, and the Indigenous Education Commons

How does access to this work benefit you? Let us know!

\section{Recommended Citation}

Hallman, Kelly, Lisa Polen, and Katey Peck. 2021. "The IMAGEN Story: A Framework for Restoring Indigenous Girl Societies.” New York: Indigenous Adolescent Girls' Empowerment Network (IMAGEN). 



\section{IMAGEN Overview}

Native girls carry immense responsibilities and face unique challenges, even within their own communities. Over hundreds of years cultural dislocation, through violent colonial policies and patriarchal norms, eroded many of the indigenous matriarchal social, political and economic structures that empowered Native women and girls. While Native girls face disproportionate health, educational, social, and economic challenges, they also do not receive an equitable share of tribal resources. In Indigenous communities, less than 10\% of programming for Native youth focuses exclusively on the needs of girls.

Created in 2017, the Indigenous Adolescent Girls' Empowerment Network (IMAGEN) brings together organizations from rural tribal and urban Indian communities to strengthen the protection, safety, and resilience of girls by reclaiming neighborhood spaces and building local female Native-led mentorship programs. Known as Girl Societies, these programs are again creating community connections and serving as platforms for transmission of tribal history, cultural knowledge, and practical skills to the next generation. Girls receive a variety of supports, as sovereignly determined by the girls of each society.

\section{The program's goals are three-fold:}

1. To restore intergenerational connections and Indigenous culture,

2. To rekindle Indigenous matrilineal leadership structures and social support networks, and

3. To empower healing from historical and modern traumas through Indigenous-led approaches.
IMAGEN is bolstered by global and local knowledge of what works best for Native Girls. The core content incorporates ancient knowledge and decades of research on Indigenous girl-centered design and programming across the Americas. It embraces a gender- and life-stage focus to support Native girls through many pivotal life events that occur during Native girls' adolescence, and has drawn from relevant cross-national tools for local use. In systematizing Native female networks, IMAGEN honors the relationships and expertise held by Native-led communities. While content and implementation are sovereignly determined, Native women leading Girl Societies receive a suite of tools and on-going supports to guide planning, implementation, and assessment.

\section{The core components of an IMAGEN Girl Society include young and adolescent girls, female mentors, elders, and a safe place to gather.}

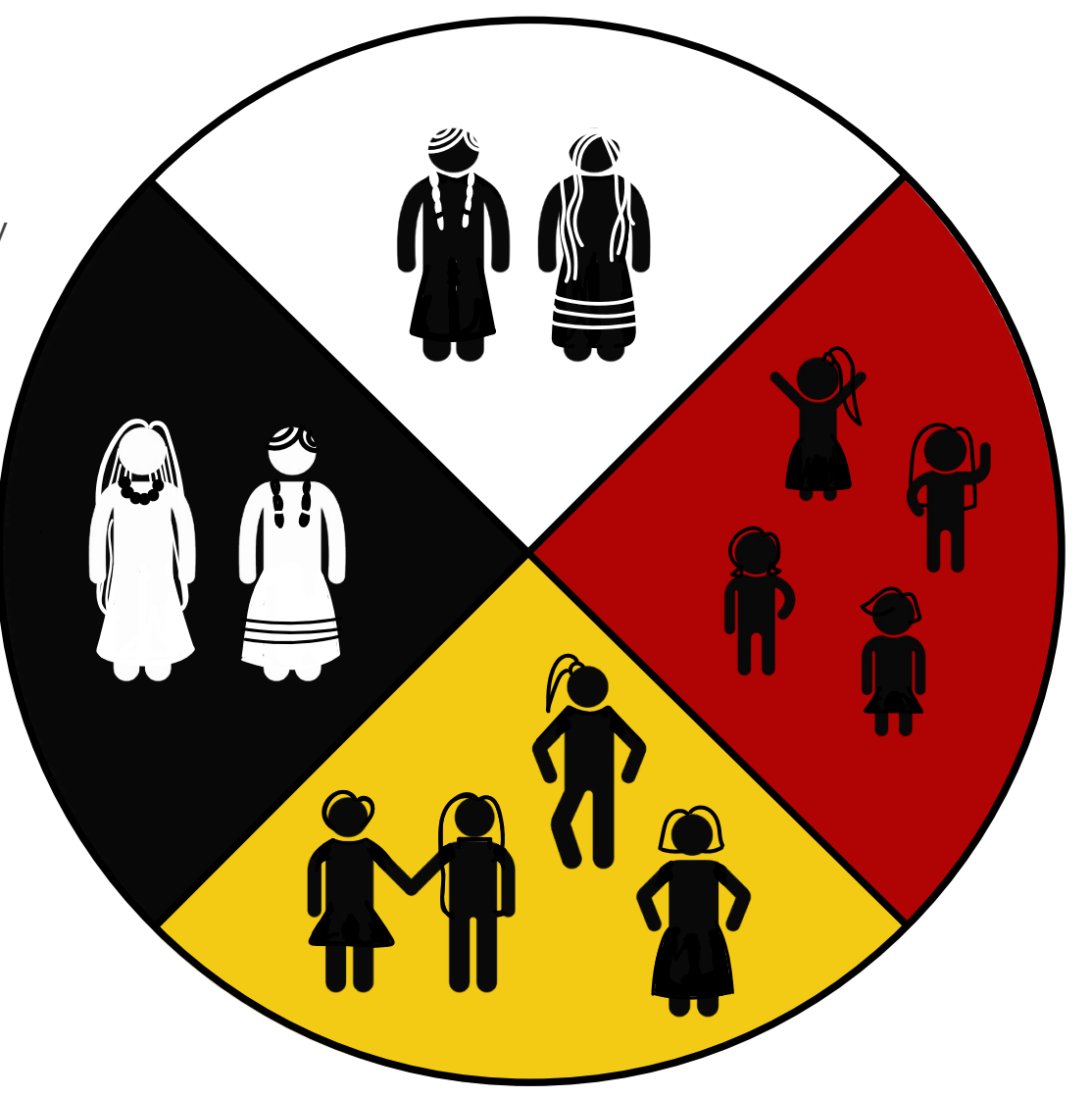




\section{To date, Girl Societies have been created in over 45 Native}

communities across the U.S.

From the group of Native partner organizations that met in 2017 to conceive of the initiative, to our primary implementation partners working in tribal communities, the IMAGEN model has continued to spread in the context of COVID-19 and is strengthened by knowledge shared among tribal communities that form the network.

Aleut Community of St. Paut Island

St. Paul, AK

Through conversations with Native female mentors of our implementing partners and ongoing meetings with collaborators across Turtle Island (North America), the IMAGEN team has collected six key lessons for building and supporting Indigenous Girl Societies.

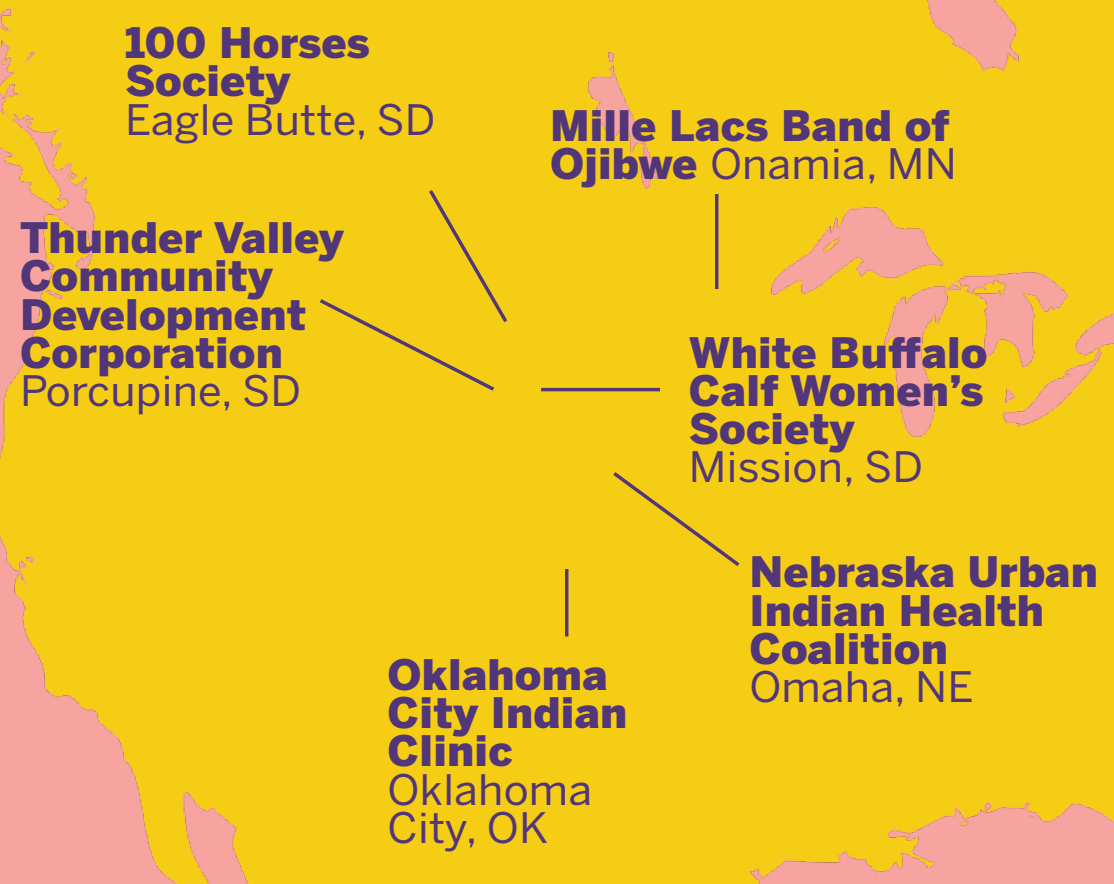




\section{Lesson 1: Embodying historical mechanisms used by Native communities to pass knowledge to the next generation, Girl Societies are eagerly embraced by Indigenous women as a decolonizing practice.}

The violent effects of colonialism continue to shape Native life, as many negotiate circular migration between under-

resourced, over-regulated rural tribal areas and urban locations seeking opportunities. Indigenous girls and women face a host of structural challenges related to domestic violence, sexual assault, human trafficking, substance use, suicide, health issues, and lack of educational and job opportunities. A common theme emerged from these partner discussions: a need to reach girls as they transition into adolescence, but an absence of existing spaces and programs that focus on their specific needs.

At the same time, Native-led organizations are well aware of the assets held by their communities, the resilience of their girls, and the possibility of alternative futures supported by local approaches and solutions. Across these communities, there is a commitment to passing down cultural knowledge and traditions to the next generation. There are Native women and older girls who care deeply about their tribes and stand ready to lead. At the core of Girl Societies is a focus on serving girls and communities as a collective. The desire and need for Native girl-centered programming is pervasive, demonstrated by IMAGEN's constantly growing engagement across Turtle Island.
Thunder Valley Community Development Corporation: Creation of Oglala Lakota Girl Society, Wóâsakè Wóohitika Hpecákesni Yuhican (Strong, Courageous, Honest, Awake)

-Identified community needs: mentorship opportunities for girls in 7th and 8th grade, after school programs, and transportation.

-Organized community-wide gatherings for citizens of Oglala Lakota Nation to discuss the possibilities for starting a Girl Society movement.

-Followed Indigenous cultural protocols for planning: food, role of cultural knowledge-bearing elders, blessings by Creator, Lakota name.

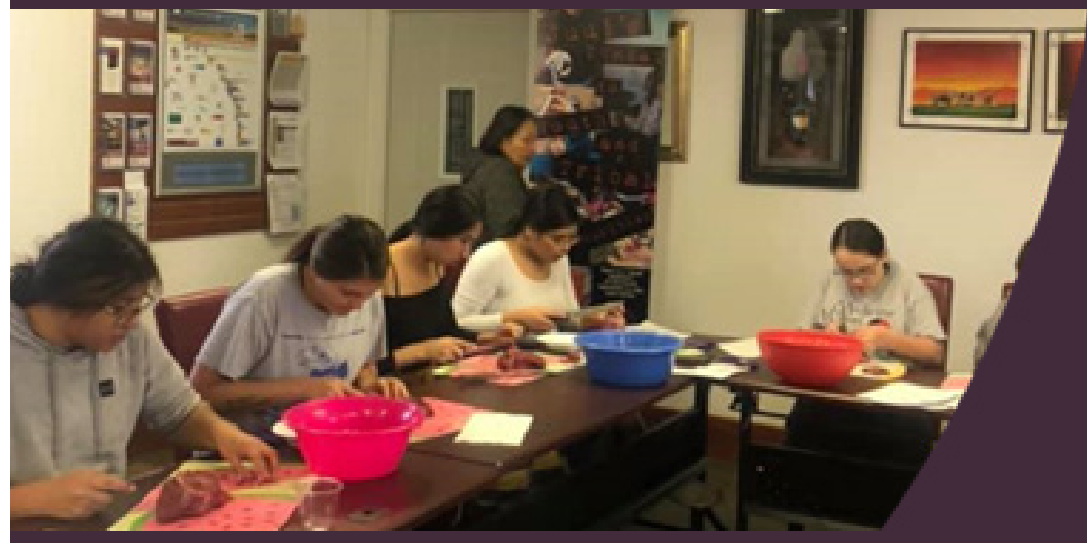

100 Horses Society: Expanding access to Isnati Ca Lowanpi (Becoming a Woman Ceremony) among Cheyenne River Sioux

- Expanded from annual ceremony preparation to monthly gatherings in multiple communities open to all girls and women interested in learning about Lakota culture.

-At "Wíkhóškalaka Iglúwitayapi” gatherings, to learn traditional teachings around womanhood, cultural survival, and values, and undertake handson activities. 


\section{Lesson 2: IMAGEN's Native-led culture- based mentorship model provides unique roles, supports, and benefits for Indigenous girls, women, and elders.}

Mentors are the backbone of the IMAGEN model and play the key role of connecting girls to each other, to their communities, and to cultural traditions. Mentors are recruited from the local community and are a mix of young, middle-aged and elder woman, each providing pathways for girls to knowledge, resources and support. To keep groups running smoothly, mentors usually work in pairs, often with a younger woman matched with an elder mentor to strengthen intergenerational ties and encourage the preservation and transfer of cultural knowledge to the next generation. This arrangement strengthens historical female leadership roles and matrilineal social structures, with three generations interacting within most Girl Societies.

Mentors receive continuous operational support and training from IMAGEN, both in-person (pre-COVID-19) and as members of the IMAGEN Circle, a gathering convened bi-weekly online. The Circle creates a nationwide indigenous female movement and provides space for mentors and program managers learn from, inspire, and honor each other. The on-going, predictably timed convenings encourage connections across diverse tribal communities and allow participants to learn from each other's experiences, share frustrations and brainstorm solutions. These conversations lead to innovation and foster the exchange and expansion of program ideas, resources, and opportunities.
Oklahoma City Indian Clinic: Sharing history and culture through MISS and Junior MISS

- Mentorship programs respond to needs of diverse urban community of over 200 federally recognized tribes, many of whose ancestors were forced from traditional lands.

- Led by Indigenous clinic staff, MISS (ages 12 to 17) and Junior MISS (ages 9-11) feature skill building and cultural activities.

- Girls from prior program cycles now serve as mentors to Junior MISS participants.

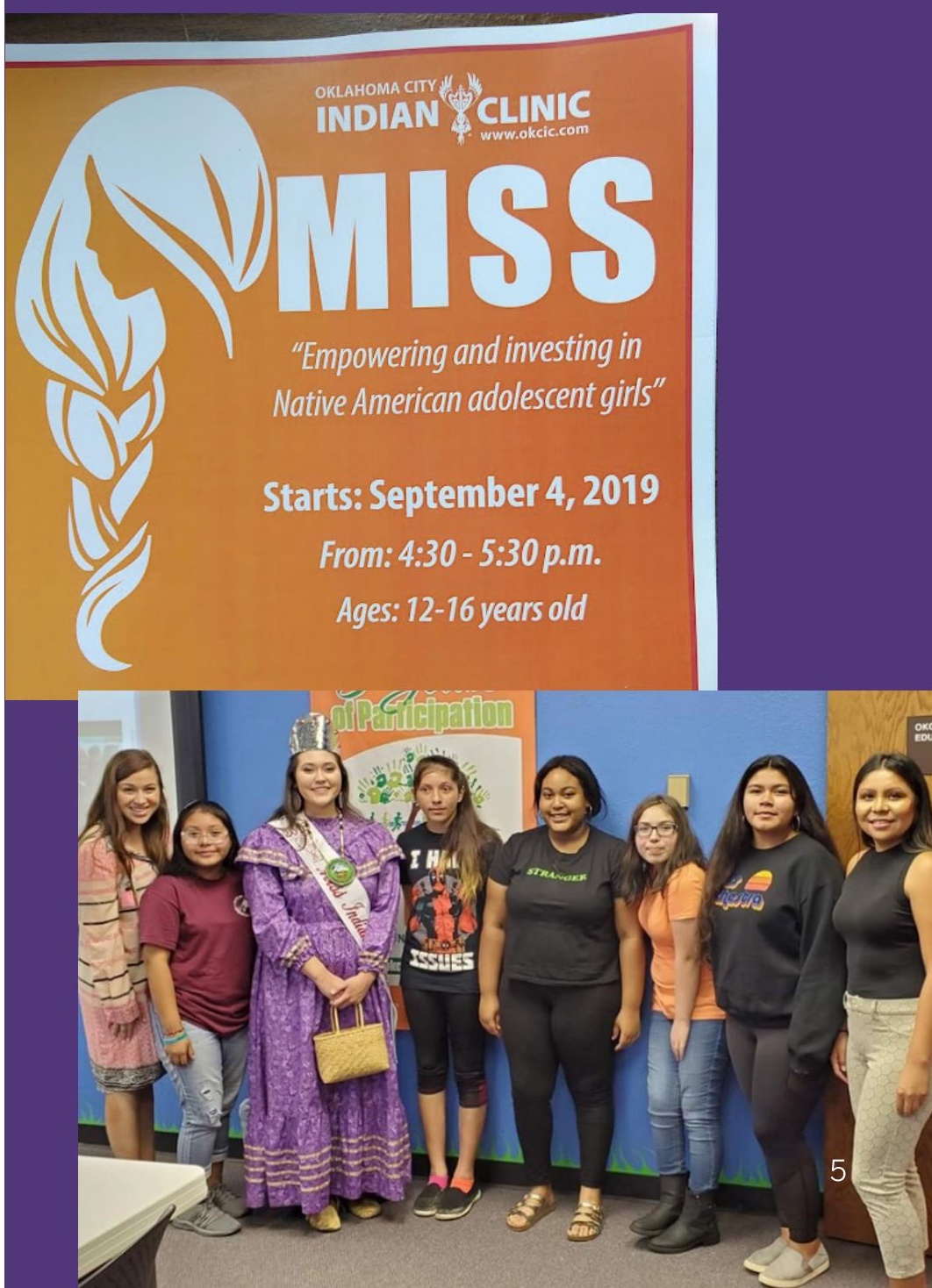




\section{Lesson 3: IMAGEN facilitates cross-tribal learning by hosting on-going exchanges among Girl Society mentors from across Indian Country.}

To guarantee that best practices and innovations are quickly available to all tribal partners, IMAGEN hosts an on-going inter-tribal exchange (virtual and in-person) among communities undertaking this work, the "IMAGEN Circle." For example, as of March 2020 when the COVID-19 pandemic began affecting communities globally, the IMAGEN Circle was opened to all collaborating organizations and convened virtually every two weeks. The Circle gatherings draw upon the wealth of real-time experiences and life-long learning of our partners. This deep connection allows Native women across the age spectrum to hear and learn from each other, offering encouragement, motivation, and ideas for program planning and girl-engagement in an informal and supportive setting. Members offer unique perspectives on the challenges of implementing girl-centered programming in their communities and find inspiration from each other's successes.

These gatherings have created opportunities for groups in the same geographic area to lay the foundation for future in-person collaboration and program expansion. In addition to the bi-weekly IMAGEN Circle gatherings, IMAGEN hosts regularly scheduled webinars featuring the work of our partners, giving each group the opportunity to showcase their accomplishments to larger audiences.

Kelsey Tangney, Oklahoma City Indian Clinic: "I know if there are ever any questions I have or brainstorming, I know I can come to you [the IMAGEN Circle] and get the help. I like hearing the other stories."

\section{Kala Roberts, Mille Lacs Band} of Ojflbwe: "The thing that has kept this [MLBO Girl Society] going has been our [the IMAGEN Circle] getting together on a regular basis.... I think I would have long given up but hearing the struggles that everyone else is having, and the idea of how their getting the girls connected has been very, very helpful... The connection was key to feeling like 6 you could keep moving."
Nicole Benegas, Nebraska Urban Indian Health Coalition: "I love getting the opportunity to hear what everyone else is doing, I love the meetings where we get to be with other Native organizations and people who are doing the work, because you don't have to repetitively have to explain what the work is. You just get to hear different ideas and you get to know where they are coming from."

\section{Aimee Pond, Thunder Valley} CDC: "I appreciate all the support we get [from IMAGEN] and the guidance, especially during this really hard time; this past year [during the COVID-19 pandemic] has been really hard."
Veronica Padula, Aleut

Community of St. Paul: "I like the [IMAGEN Circle] gathering calls, I get a lot of inspiration and ideas from other groups, what activities they are doing and how they can be adapted to the girls we work with."

\section{Medina Matonis, 100 Horses} Society: "We're grateful for the community and I love connecting with all these amazing women. Wopila Tanka to the IMAGEN team for your part in planting the seeds for our 50-year story and for guiding us on our journey to foster more empowered, supported and resilient women and girls on CST [Cheyenne River Sioux Tribe]." 


\section{Lesson 4: Girl Societies are tailored to}

community assets and interests. In many contexts, IMAGEN partners benefit from the support of school or community

\section{spaces.}

The IMAGEN model, while supported by a global indigenous evidence base, is designed to be intentionally responsive to local context and highly respectful of Native lifeways. While core elements of Girl Societies are present across tribal communities, such as the importance of a safe gathering space and relationships cultivated among mentors and girls, implementation relies heavily on existing local activities and resources. In some communities, Girl Societies have been incorporated into coming-of-age ceremonies and other cultural practices. In others, they have been integrated into during- and after-school programming both at tribal day schools, as well as Native-run boarding schools in very remote communities. In urban centers, they have been woven into health center programming for adolescents focused on building healthy habits. They have also been linked to existing programs focused on treatment for substance use disorders, as well as domestic violence and sexual assault. Girl Societies have served girls in tribal juvenile detention centers, and those on probation who needed a community service activity in order to re-enter school.

Many Girl Societies have utilized schools and community centers to gather inperson, as they are centrally located, known and accessible to girls and their families. Integrating activities either during or after school hours was observed to have respective benefits and drawbacks, in terms of reaching girls in a regular way, while potentially competing with other necessary educational content. It was recommended that provision of school credit, as well as curriculum accreditation, can help to expand buy-in on the part of organizations and among high-school and college-going mentors.

\section{Mille Lacs Band of Ojlbwe: Leveraging} community spaces to support Native girls

-Responding to interest among 9-13-year-old Native girls, established mentor pairs between older adolescent girls and Native adult women and elders.

- To support older adolescent girls as mentors, now provide academic internship credit through Tribal Schools.

- Given limited options for meeting space, Gir Society gatherings take place weekly during school cultural hour, or at community culture centers, with transport provided to ensure safety.

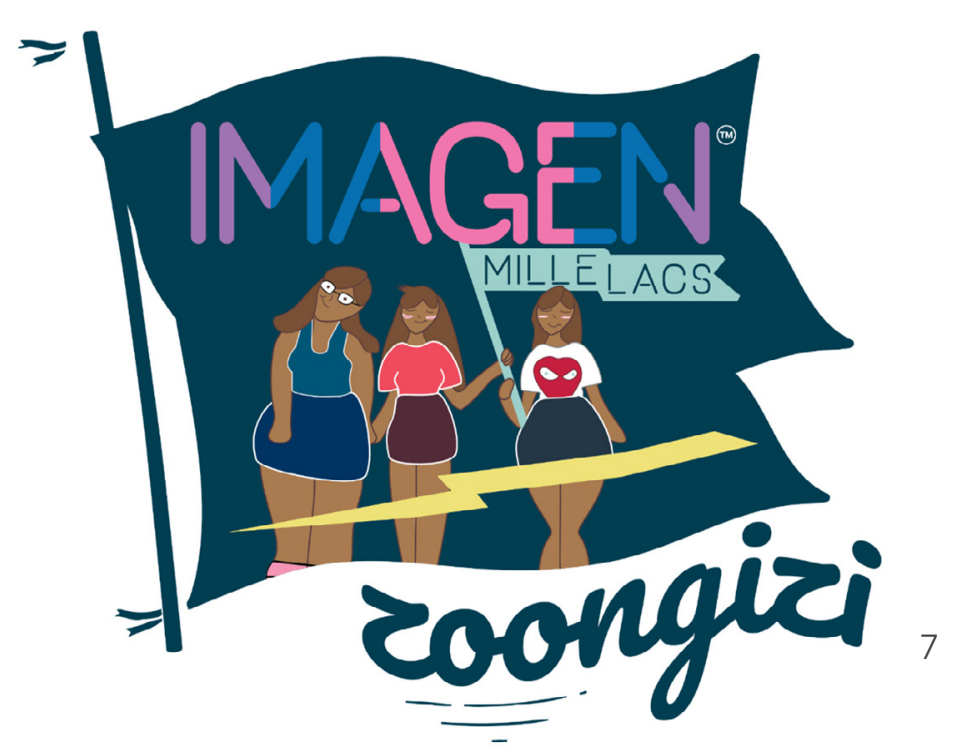




\section{Lesson 5: IMAGEN helps Native communities make female inter- generational mentorship more reliably and systematically available. By increasing access among the least connected and upholding cultural traditions, Girl Societies are resoundingly inclusive.}

IMAGEN helps Native communities make female inter-generational mentorship more reliably and systematically available, increasing access among the most marginalized and least connected. IMAGEN's approach is gender-expansive and identity inclusive, designed to reach two-spirit and LGBTQ+ youth, Indian Child Welfare Act (ICWA) girls, as well as those who are justice system involved, recovering from substance use, at risk for school dropout, and most at risk for trafficking.

While IMAGEN spaces are referred to as Girl Societies, community programs have adapted an expansive and inclusive approach that transcends colonial gender binaries. When asked about the participation of two-spirit, non-binary, transgender, Indian Child Welfare Act, and non-Native girls, mentors had often already welcomed these groups into their spaces. When faced with questions or resistance from individual girls, mentors, or community members, elders reported embracing traditional indigenous cultural attitudes to educate on the historically revered status of gender-expansive persons. Prior to the COVID-19 pandemic, Girl Societies were already being held in juvenile detention centers and among girls on school probation; however, the pandemic allowed the opportunity to further expand offerings to such girls.
As meetings were held virtually, mentors were able to connect with girls in residential boarding schools, substance abuse programs, juvenile detention facilities, and geographically isolated girls in remote areas. This opportunity allowed programs to rethink and expand their approach.

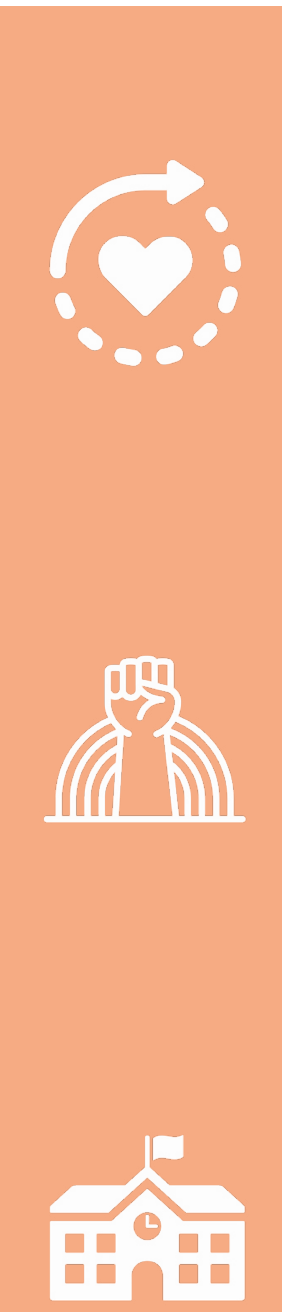

White Buffalo Calf Women's Society (WBCWS): On the Rosebud Sioux Reservation, Wicincila Society meetings have been held in juvenile detention centers and local schools, supporting healing and restorative justice practices.

Nebraska Urban Indian Health Coalition (NUIHC): Serving the Omaha metro area, NUIHC staff are trained and certified as Two-Spirit traditional teaching educators and have opened Girl Society activities to anyone who identified as female, two-spirit, or non-binary.

The Aleut Community of St. Paul Island, Alaska: Girl Societies pair St. Paul Island high school girls in boarding schools on the Alaska mainland with younger girls still living on the Pribilof Islands to support cultural and community connections. 


\section{Lesson 6: Girl Societies, like Native communities, remain resillient and adaptable in the face of COVID-19, embracing new approaches to support digital engagement.}

Even prior to the pandemic, IMAGEN partners were addressing a variety of challenges to maintain Girl Societies. Especially in the reservation context, providing reliable transportation to ensure groups were inclusive of girls living in different communities has proven logistically complicated. For Native-led and tribal organizations, staff turnover is often high due to health and financial difficulties combined with staggering service gaps. While there is often excitement to establish a Girl Society, high responsibility loads of capable community members impact recruitment and retention of mentors. In the COVID-19 context, a lack of internet and device access in some rural, remote communities has hampered the shift to weekly virtual engagement. And, as families and girls are facing heightened levels of social isolation, financial hardship, and loss of family members to COVID-19, there is even greater need for basic supports amidst less bandwidth to meaningfully engage.

Despite these many challenges, IMAGEN partners have continued to act creatively and share solutions among the IMAGEN Circle for meeting the needs of girls in their communities. Use of Zoom, Facebook, and Google Meet have helped engage harder to reach girls. It is widely recognized that even as in-person meetings resume, these digital platforms will be key to reaching geographically isolated groups, making Girl Societies even more connected and inclusive. Use of Facebook has taken off across several communities, with groups posting photos and sharing about favorite activities, such as virtual cooking, sewing and beading lessons by mentors. In addition to leveraging technology to bring together larger groups of girls, mentors have also adapted to reach girls for individual checkins. Depending on preference and level of comfort, weekly check-ins by phone have helped to keep girls and their families connected in a time of profound isolation.

\section{Supporting Girls Through COVID-19:} Example Activities

- Virtual Girl Society meetings offered to girls with a cell or broadband connection.

- Masked in-person porch visits to check-in with those without cell or broadband.

-Promotion of outdoor activities such as hiking, fitness activities and self-defense instruction.

- Emergency packages available for pick up or drop off during lock down periods.

-Pen-pal activities kept girls and mentors without cell or broadband connected.

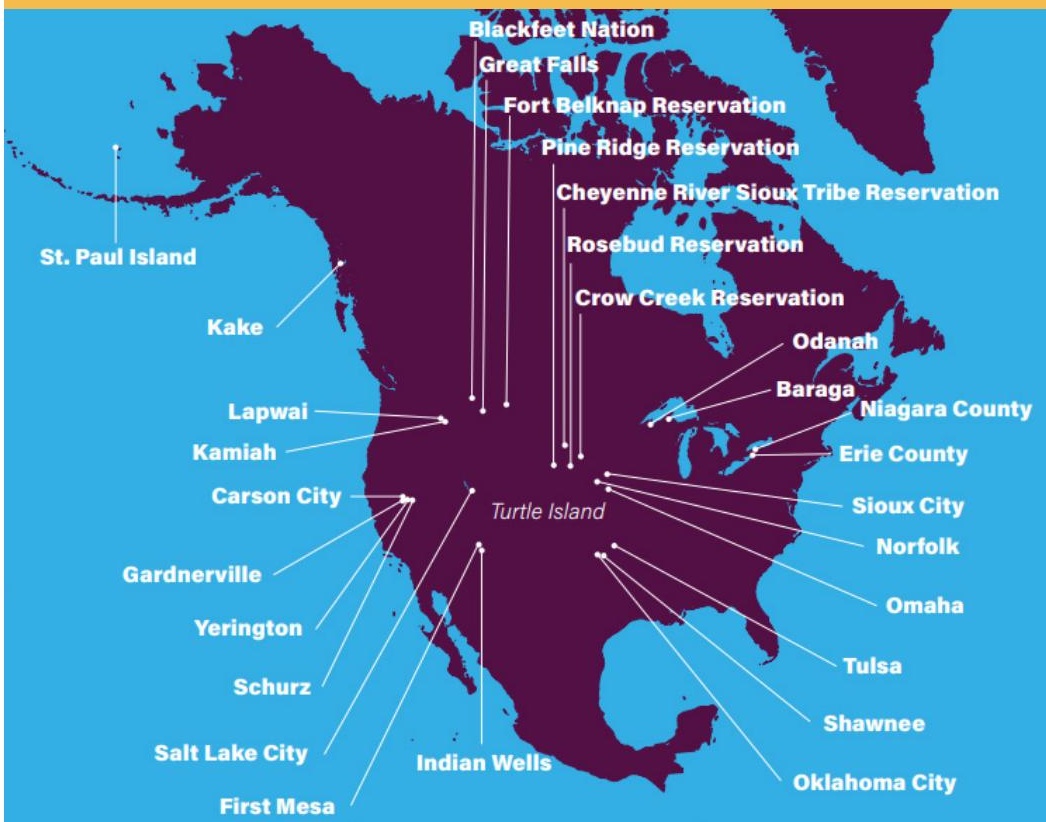




\section{Looking Forward}

There is hope and excitement across Girl Societies that resuming in-person gatherings will help to re-energize and heal Native communities that have been disproportionately affected by the COVID-19 pandemic. With the loss of many tribal elders, there is acknowledgement among mentors and communities that this work remains essential both to preserving cultural traditions and supporting the next generation of Native women.

There are several areas of anticipated growth for the network, including:

1. Additional resource documents and "how-to" tools to support new and existing Girl Societies.

2. Strengthened content to promote skills building and inclusivity.

3. Enhanced monitoring and evaluation tools, to strengthen activities and document impact.

4. Generating new evidence to improve understanding of the needs of Indigenous adolescent girls.

5. Addressing challenges related to circular migration by strengthening links between urban and rural mentors and resources.

As IMAGEN continues to grow, there is a desire among Native women and organizations to continue to connect and exchange ideas with other Girl Societies and Indigenous groups. In addition to regular IMAGEN gatherings, there have been several international exchanges between mentors from Native American and Mayan communities, where women have learned and drawn strength from their shared contexts. While supporting the needs of individual Girl Societies remains essential, connecting Native communities across Turtle Island and beyond remains an important feature of this collaborative approach.

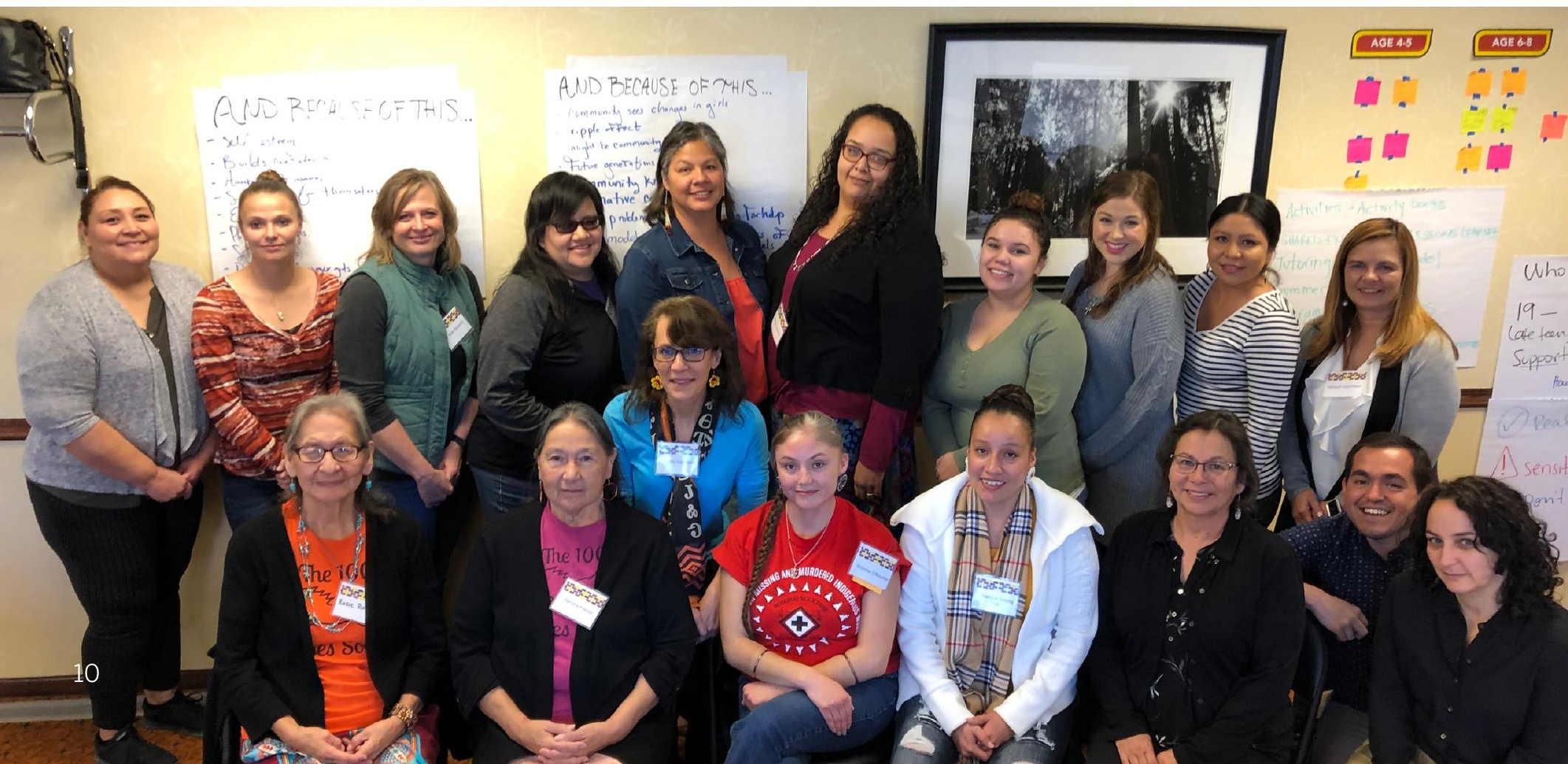




\begin{tabular}{|c|c|}
\hline \multicolumn{2}{|c|}{ For more information, please visit IMAGEN and refer to the following resources: } \\
\hline Tools & $\begin{array}{ll}\text { - } & \text { Resilience Skills Challenge Game } \\
\text { - } & \text { Girl-Centered Participatory Assessment Tools }\end{array}$ \\
\hline Briefs & $\begin{array}{ll}\text { - } & \text { Supporting Native American Girls During the COVID-19 Pandemic } \\
\text { - } & \text { Returning to Matrilineal Traditions, Building a New Generation of Indigenous Girl } \\
\text { - } & \text { Societies } \\
\text { - } & \text { Geclaiming Matrilineal Traditions \& Building Girl Societies in Indigenous Montana } \\
\text { - } & \text { Building Indigenous Networks in South Dakota } \\
\text { - } & \text { Adapting the Girl Roster for Lakota Communities } \\
\end{array}$ \\
\hline Webinars & 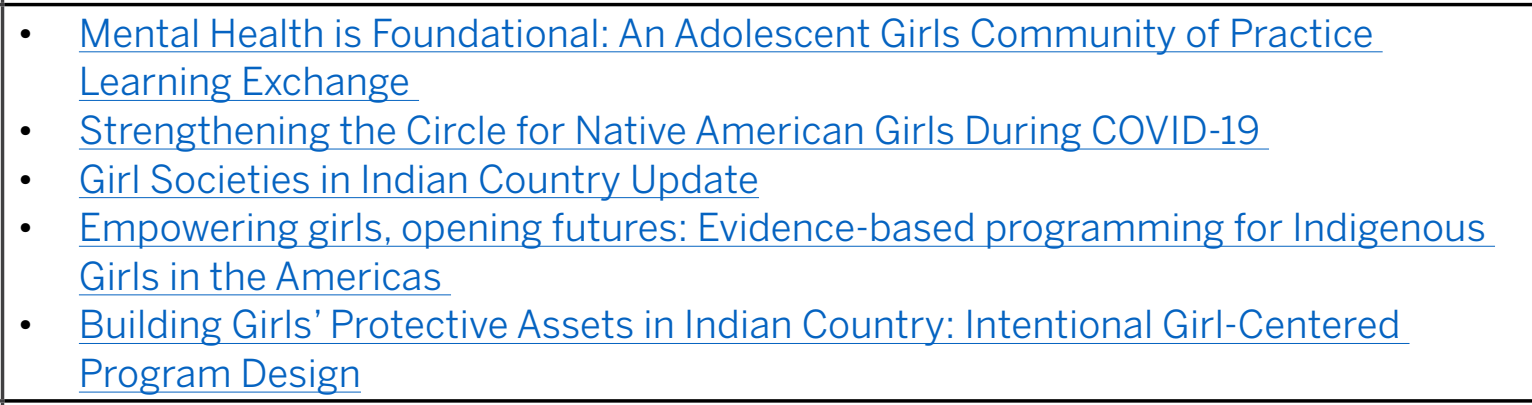 \\
\hline Other & 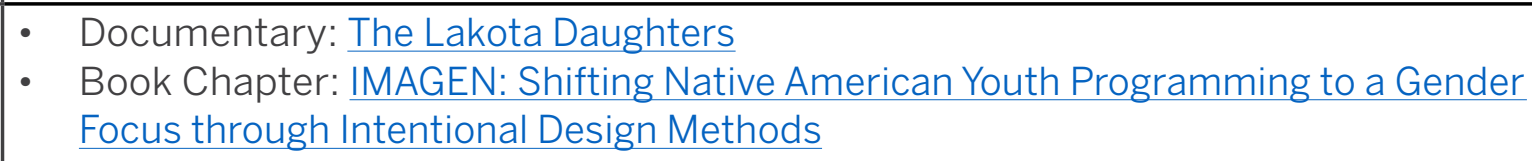 \\
\hline
\end{tabular}

Acknowledgements (alphabetical by surname): Arlana Bettelyoun, Kellee Brewer, Ruth Cedar Face, Lindsey Compton, Kassel Franco Garibay, Sandy Frazier, Mariah LaPointe, Mary Jo LeBeaux, LeToy Lunderman, Erika Martin, Stephanie Martinez, Medina Matonis, Meagan Mahtushquah, Sonia Merculief, Gwendolyn Packard, Veronica Padula, Michaela Parrott, Aimee Pond, Courtney Reeder, Kala Roberts, Ashley Rogers, Janet Routzen, Sharisse Sitting Bear, Gwen Small Bear, Nicole Tamayo-Benegas, Kelsey Tangney IMAGEN is made possible through generous funding from The Ford Foundation, Novo Foundation, the ForGood Fund, Marty Jeiven, and the Cunningham Family.

Suggested citation: Hallman, K., Polen, L., Peck, K. 2021. The IMAGEN Story: A Framework for Restoring Indigenous Girl Societies. NY, NY. Indigenous Adolescent Girls' Empowerment network (IMAGEN).
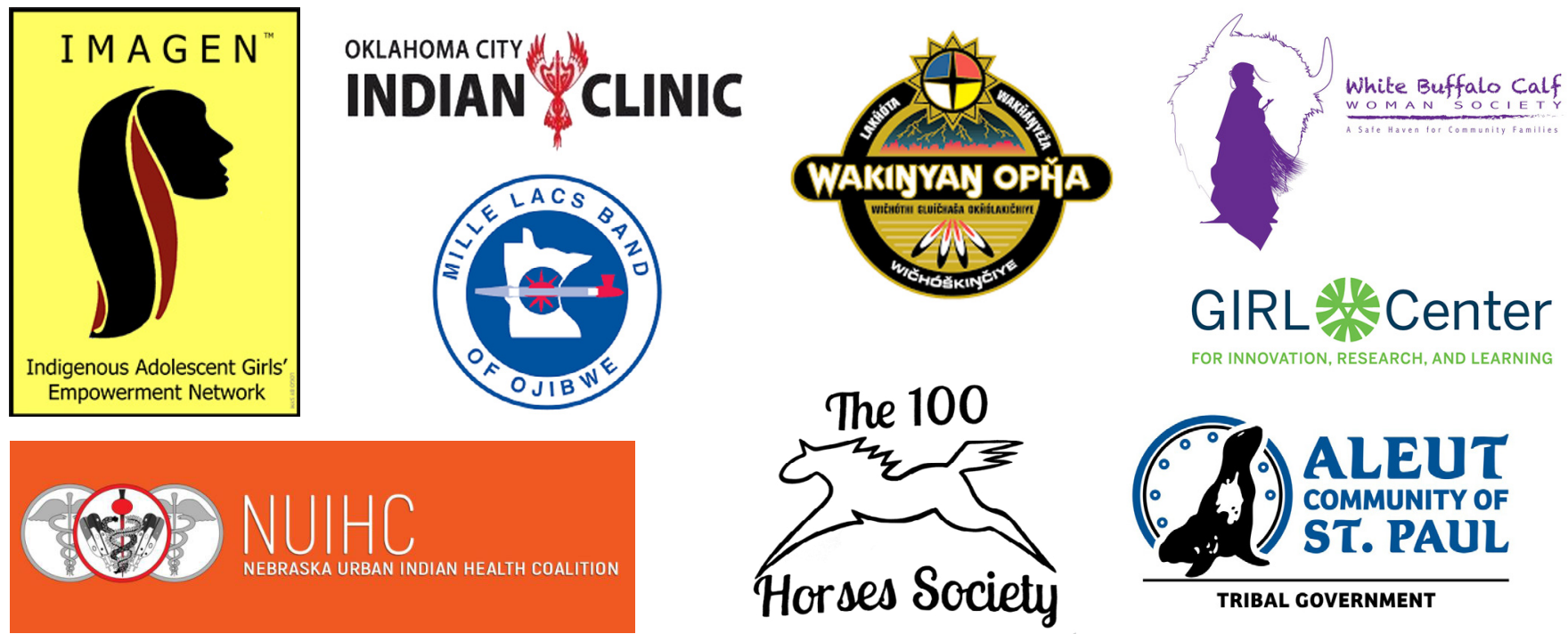